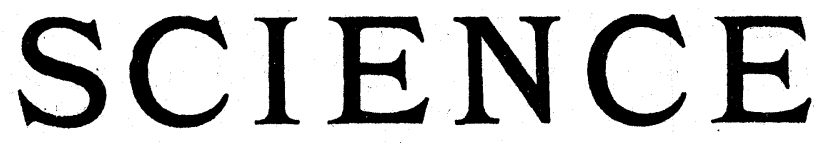

Editorial Committee : S. Newcomb, Mathematics; R. S. Woodward, Mechanics; E. C. Pickering, Astronomy; T. C. Mendenhall, Physics; R. H. Thunston, Engineering; Ira Remsen, Chemistry;

J. Le Conte, Geology; W. M. Davis, Physiography; O. C. Marsh, Paleontology; W. K. Brooks,

C. HART MerriaM, Zoology; S. H. Scudder, Entomology; C. E.' Bessey, N. L. Britton,

Botany; Henry F. Osborn, General Biology; C. S. Mrnot, Embryology, Histology;

H. P. Bowditch, Physiology; J. S. Brluinas, Hygiene ; J. McKeen Catteli, Psychology; Danike G. Brinton, J. W. Powkll, Anthropology.

Friday, December 10, 1897.

CONTENTS:

The Revival of Alchemy: H. CARRINGTON BoLTON.

science in Education: S. W. WILLISTON .863

Current Notes on Physiography:-

The Regions about Lakes Tanganyika and Nyassa;

Brïckner's Erdrinde und Ihre Formen; The Age of Valleys: W. M. DAvis.

Current Notes on Anthropology:-

The Question of Variation; The City of Omitlan;

The Cave of Loltum: D. G. BRINTON. .873

Notes on Inorganic Chemistry: J. L. H .874

Ecientific Notes and News .875

University and Educational News. .878

Discussion and Correspondence:In Regard to the Marine Biological Laboratory, Woods Holl, Mass.: SAMUEL L. ClaARKe, Edw. G. Gardiner, Playfair McMurrich..879

Scientific Literature:-

Ehrenreich's Anthropologische Studien ueber die Ureinwohner Brasiliens : D. G. BRINTON, FRANZ BoAs. Maycock on the Alternating Current Circuit : FReDerick BeDeLL. Behrens' Anleitung zur Mikrochemische Analyse der wichtigsten organischen Verbindungen; Lassar-Cohn's Chemie im täglichen Leben: E. R.

Societies and Academies:-

The Nebraska Academy of Science: G. D. SwEZEY. Biological Socicty of Washington: F. A. LUCAs. Zoological Club of the University of Chicago : W. M. WHEELER, S. J. HOLMES.

Scientific Journals.

New Books.

MSS. intended for publication and books, etc., intended for review should be sent to the responsible editor, Prof. J. McKeen Cattell, Garrison-on-Hudson, N Y.

\section{THE REVIVAL OF ALCHEMY**}

"Superfluous rehearsalls I lay asyde, Intendyng only to give trew informatyon Both of the theoryke and practicall operatyon ;

That by my wrytyng who so will guyded be,

Of hys intente perfyctly speed thall he." George RIPLEY (1471).

Fraud, folly and failure have been deeply written into the annals of alchemy in all ages; it was early characterized as an 'art without art, beginning with deceit, continued by labor and ending in poverty, and in modern times its extravagant pretensions have been condemned by an exact and critical science, yet notwithstanding there are to-day indications of a resuscitation of the captivating theories and of renewed attempts at their practical application, of great interest to students of the intellectual vagaries of mankind.

Belief in the possibilility of prolonging life by an artificial elixir and of transmuting base metals into silver and gold was generally entertained in the Middle Ages, not only by the ignorant masses, but even by serious-minded philosophers imbued with all the learning of the time ; and the popular faith was sustained by the tricks of unprincipled impostors who found it profitable to prey upon the credulity and avarice of their fellow men. Those who in

* Read before the New York Section of the American Chemical Society, October 1, 1897. 
modern times have written of alchemists find in the extravagant views of a Paracelsus, and in the careers of a Flamel, a Sendivogius, or of a John Dee, more entertaining materials than in the abstract conceptions of sober philosophers, and consequently most readers are more familiar with the misdeeds of adventurers than with the honest beliefs of respectable men of science. Before condemning those who labored day and night to solve the problems of transmutation and the elixir of life we should consider their intellectual environment; superstitious beliefs of every kind prevailed; even the sciences were in bondage; astronomy was dominated by astrology; medicine was influenced by magic ; natural history was subject to blind belief in authorities, and scientific chemistry was entirely overwhelmed by the chimeras of alchemy. Kepler and Tycho Brahe, at the Court of Rudolph II., did not think it beneath their dignity to cast horoscopes for gain and to predict the future by consulting the positions of celestial bodies, even while formulating the laws governing their motions. European crowned heads retained astrologers and alchemists as members of their courts. A century later Sir Isaac Newton dabbled with furnaces and chemicals in true hermetic style; and Leibnitz showed the courage of his convictions by acting as Secretary of an Alchemical Society in Germany. The influ. ence of superstition on the mental attitude of truly great men decreased with the advancement of learning, and when the foundations of scientific chemistry were laid by Priestley, Lavoisier, Scheele and their contemporaries, the doctrines of alchemy were abandoned. And yet not wholly abandoned, for there seems to have been a small number of persons in all countries who have clung to the hope of realizing transmutation, a hope sustained by the desire to reap the golden reward. This minority rejected the extravagant belief in a life-prolonging elixir, and in the divine origin of the profound secrets of the initiated, and sought to appropriate from the growing sciences such discoveries and theories as could be interpreted in favor of transmutation.

The printing press has never ceased to issue works devoted to the subject. Some authors have written of a 'higher chemistry,' and others have sought to reconcile. the new doctrines of chemists with the ancient theories of alchemists. As recently as 1832 a German professor wrote a learned volume with the avowed intent of proving the verity of transmutation from historical sources (Schmieder's Geschichte der Alchemie, Halle, 1832). The number of reprints of the grotesque writings of reputed adepts which have appeared since chemistry has become an exact science is surprisingly large, and the fact that they find purchasers indicates a small but zealous class. of hermetic students. So eminent a chem. ist as Sir Humphry Davy did not hesitate to affirm that some of the doctrines of alchemy are not unphilosophical.

Recent discoveries in physics, chemistry and psychology have given the disciples of Hermes renewed hopes, and the present position of chemical philosophy has given. the fundamental doctrine of alchemy a substantial impetus; the favorite theory of a prima materia, or primary matter, the basis. of all the elementary bodies, has received new support by the discoveries of allotropism of the elements, isomerism of organic compounds, the revelations of the spectroscope, the practical demonstrations by Norman Lockyer, the experimerits on the specific heat of gaseous bodies at a high temperature by Mallard and Le.Châtelier, the discoveries of Sir William Crookes as set forth in his monograph on 'Meta-elements,' the diseovery by Carey Lea of several singular allotropic forms of silver, and, most. 
weighty of all, the mass of related facts and phenomena which find their ultimate expression in the Periodic Law of the Elements, so that many chemists of the present day are inclined to believe in the mutual convertibility of elements having similar chemical properties. Daniel Berthelot, in his notable work entitled ' De l' allotropie des corps simples,' boldly affirms his belief in the unity of matter. He says: "Without seeking to find in any one of the known elements the generator of the others, can we not invoke the facts that we have revealed in our study of carbon, in favor of the hypothesis of a unique matter unequally condensed ?" And elsewhere he writes: "The transmutation of an element is nothing more than the transformation of the motions which determine the existence of said element, and which gives it special properties, into the specific motions peculiar to the existence of another element."

Simultaneously with the development of the truly scientific aspect of alchemical theory, there has arisen an extraordinary revival of the metaphysical side of the question; this goes hand in hand with the interest in chiromancy, astrology, theosophy and occult sciences which occupy so large a place in modern thought, literature and polite society on both sides of the Atlantic. This tendency to cultivate the esoteric manifests itself in the study of the Kabala, the investigation of the mysteries of Buddhism, Confucianism and other oriental philosophies, in researches into the phenomena of spiritualism so-called, and in the foundation of societies to study Psychic Force and the tenets of the followers of Madame Blavatsky; crystal-gazing, reading in magic mirrors, slate-writing, planchette, the quasi-scientific study of apparitions, of table-turnings, of rappings by unseen powers, of telepathy, of subliminal self, are now regarded as legitimate pur. suits in no wise necessarily associated with the black arts of mediæval times, provided only they are conducted in a spirit of enquiry and for the purpose of discovering the latent power underlying these phenomena. And this line of research receives stimulus from the results secured by stu. dents of experimental psychology, of hypnotism, from such discoveries as the phenomena of the X-rays, and from the transcendental physicists who theorize on the miraculous consequences of four dimensional matter. Crowded lecture halls reward exhibitions of trance mediums, speakers on theosophy, palmistry and occultism; in lower walks of life fortune-tellers and clairvoyants reap a modest harvest; books treating of occult themes enjoy great notoriety; writers of fiction find it profitable to introduce the mysterious into the children of their brains ; even secular journals, especially those of France, give space to the all-absorbing discussions on hermetism ; these are some of the evidences of great popular interest in the unknowable. Only persons with special intellectual equipment are able to measure, weigh, sift and coordinate the novel phenomena gathered by researches in the field of hypnotism, psychology and occultism; those of weaker mental powers fail to perceive the real significance of the discoveries and are led away into unprofitable and dangerous superstitions.

In the Middle Ages alchemy was nurtured by ignorant superstition; now it is fostered by the prevalent devotion to esoteric studies; formerly the popular belief was in part supported by the fraudulent claims of impostors; now a higher standard of intelligence rejects the transparent tricks of imitators of Cagliostro. There are, indeed, occasional attempts to swindle the credulous by appeals to avarice; we read in the daily press of an American confidence-man who tried to cheat a London jeweler by pretending to 'multiply' sovereigns; of a 
vulgar scheme of fraud among ignorant tradesmen on the east side of New York City, in which lead, iron scraps, crucibles and furnaces formed the properties; and of the larger operations of an educated French chemist who found dupes in both South and North America; but in each of these cases the severe logic of law courts intervened and abruptly discomfited the swindlers. It is not by sleight-of-hand that the revival of alchemy is now being engineered, but by a company of educated charlatans.

The movement to resuscitate alchemical doctrines and practices has been particularly successful in France, where there are to-day four societies and a ' university' claiming to possess occultknowledge of hermetic mysteries; these secret societies are named: ' Ordre de la Rose-Croix, 'L'Ordre Martiniste,' 'La Société d' Homéopathie Hermétique' and ' $L$ ' Association Alchimique de France.'

The first two of these societies seem to work on lines similar to Free Masonry, and claim that their secret mysteries were bequeathed by the last sages of Atlantis and by the Lemures to their brethren in Asia and Egypt, dwellers in sanctuaries whence issued Krishna, Zoroaster, Hermes, Moses, Pythagoras and Plato. The priestly Magi who preserved this lore in the temples of Thebes, Heracleopolis, Aphrodite, Pthah and Serapis were succeeded by secret alchemical societies of the first centuries of our era; then followed the Hermetic lodges of the Arabs, and these gave rise to the Templars, the Rosicrucians and the Martinists.

The third society cultivates especially occult therapeutics, a system of medicine invented in the sixties by Count Crsar Mattei, of Bologna, which unites the principles of Hahnemann with those of the Iatro-chemists, disciples of Paracelsus. This new departure in medicine publishes four monthly organs and special treatises all its own.
The Alchemical Association of France is successor to the Société Hermétique, which was founded by the late Albert Poisson $(\dagger 1894)$, also known by the pen-name Philophotes. Its seat is in Paris ; the objects of the Association as set forth in its Constitution are "the theoretical and experimental study of evolution and of the transmutation of bodies. Its members, with this end in view, study the processes of the ancient alchemists and compare them with the work of modern chemists." These objects are to be accomplished as follows: "The Association proposes to assist in reviving the unitary doctrines of chemistry: 1st, by grouping the efforts of isolated workers by means of L'Hyperchimie ; $2 \mathrm{~d}$, by furnishing them the aid of advanced students ; 3d, by supplying so far as possible books and apparatus to its members. Researches of the members, when approved by the Masters, should be forwarded in duplicate to the Secretary-General; one will be printed in $L^{\prime} H y p e r c h i m i e$, and the other will be preserved in the archives of the Association for the benefit of members who can secure it on demand." "Candidates for admission must pass an examination in: 1st, the theory and history of alchemy ; and $2 d$, the elements of physics and of chemistry (without mathematics). A diploma from a normal, polytechnic or industrial school will be accepted in place of No. 2."

The affairs of the Association are controlled by the Secretary-General, F. JollivetCastelot (of Douai), assisted by seven Councillors, who hold an annual meeting. There are at present (July, 1897) two Honorary Members, Camille Flammarion, the popular writer on astronomy, and $\mathrm{Au}-$ gust Strindberg, a Swede residing in Austria, author of several hermetic essays.* There are two other classes of members,

* Dr. Stephen H. Emmens, of New York, has been added to the list of honorary members since writing the above. 
masters (maîtres), who are chosen from the ordinary members by the Council after an examination of their writings; and ordidinary members (membres adhérents), of which the number is unlimited. Modest dues entitle the members to the organ of the Association, L'Hyperchimie, a monthly review of alchemy and hermetism founded in 1896.

The Councillors of the Alchemical Association have combined with the active members of the other Societies named to establish a Université Libre des Hautes Études. At present this includes three Faculties :

I. Faculté des Sciences Hermétiques, of which the Association Alchimique forms a section. The director of this Faculty is Dr. G. Encausse, and the course of instruction embraces the study of the Tarot, alchemical philosophy and practice, occultism, mysticism, Hebrew, etc. ; the curriculum leading to the ' baccalauréat-en-Kabbale' is under the supervision of the Group of Esoteric Students, while candidates for the degrees of master and doctor are under the direction of the Martinist Order.

II. Faculté des Sciences Magnétiques, represented by the École de Magnétisme de Paris, and under the direction of M. Durville; it has branches at Lyons, Bordeaux and other cities.

III. Faculté Spirite, comprising several sections of Spiritism.

Each Faculty preserves complete independence, being ' united only by moral bonds destined to hasten expansion of the rational spiritualistic movement.'

The nature of the instruction given at this University will appear in the review of the philosophy of its promoters.

The leading spirits in these secret societies and in this University are as follows: F. Jollivet-Castelot, Secretary-General of the Alchemical Association, special delegate to the Supreme Council of the Martinists, editor of L'Hyperchimie, and author of
' Comment on devient Alchimiste,' 'L'Hylozoisme' and other alchemic treatises; Dr. M. H. E. Lalande, whose pen-name is Mare Haven; F. Ch. Barlet, author of 'Essai sur l'Evolution de l'Idée ;' Dr. G. Encausse, who generally conceals his identity under the signature Papus, is President of the Esoteric Group,* President of the Supreme Council of the Martinists and the author of sixteen treatises on hermetism and magic, among which may be named 'Traité élémentaire de Magie Pratique.' Papus is also editor of L'Initiation, a journal devoted to theosophy, magic and occultism, and of Le Voile d'Isis a weekly review of spiritualism. Stanislas de Guaita is best known as the author of 'Le Temple de Satan,' ' Clef de la Magie Noire,' and ' Le Probleme du Mal,' works dealing with sorcery, the astral light in man and other mysteries. Marius Decrespe's essay on 'Les Microbes de l'Astral,' Paul Sédir's ' Les Incantations' and Albert de Rocha's 'Exteriorisation de la Motricité' are works which indicate the mental attitude of those engaged in the revival of alchemy and hermetism. A bibliography of this class of works is here out of place ; a single trade catalogue enumerates one hundred and twenty titles, chiefly of recent date.

One of the oldest workers in the Alchemical Association is the 'Master' Théodore Tiffereau; in 1854-55 he sent to the French Academy of Sciences six memoirs in which he claimed to have discovered a method of converting silver into gold. Tiffereau had made his experiments in Mexico at great expense, supporting himself meanwhile by taking daguerreotypes. His process was repeated at the Mint in Paris before the as-

* The Groupe Indépendant d'Études Ésotériques has 1,600 members, 104 branches and correspondents. It embraces members of the following societies : Ordre Martiniste, Ordre Kabbalistique de la RoseCroix, Église Gnostique, Société Alchimique de France. Membership is free. 
sayer, M. Levol, but with little success. The substance of his memoirs was published in $\mathbf{1 8 5 5}$ in a volume entitled 'Les Métaux sont des Corps Composés ;' of this a new edition was published by Lermina in 1889 . Tiffereau has never abandoned his claim, and as recently as October, 1896, he addressed another memoir to the Academy, in which he attempts to prove that the metal aluminum is a compound. Briefly stated his process is as follows : He placed in a stout glass tube a piece of aluminum foil with pure nitric acid and sealed the tube hermetically. He then exposed the tube and contents to the sun's rays during two months; at the end of this time he opened the tube ; it gave out an odor which he thought was due to ether, and it yielded a few grammes of crystals which he thought tasted like acetic acid. Since both ether and acetic acid are compounds of carbon, Tiffereau concluded that this element was derived from the aluminum. Analytical chemists would criticize this experiment in several points ; they would say Tiffereau did not demonstrate the absence of carbon in the metal used, and that he depended upon smell and taste for proofs of the carbon compounds; the tongue and the nose are incontestably useful adjuncts to the reagents of a chemical laboratory, but additional tests for ether and acetic acid would have been more conclusive. In Tiffereau's recent writings he attributes the transmutation of a base metal into the most precious one, to the action of the ' $\mathrm{mi}$ crobe of gold.'

For a student of chemistry to read, digest and write down in intelligible language, in a limited space, the principles of this new school of chemical philosophers is a difficult task, even for one somewhat familiar with the literature of the ancient alchemists; consequently the following analysis falls far short of the ideal. It is properly the work of a kabalist, a theosophist and a magician, proud designations which the writer disclaims. The modern alchemists accept all the traditions of their ancient predecessors, but give them a new significance, and interweave the novel phenomena derived from researches in pure science. They claim that during the fourteenth, fifteenth and sixteenth centuries the official schools of instruction taught exclusively the physical part of the sciences, and that the metaphysical part (which is the real life and soul of the study) has been rejected under the opprobrious name of occult science. This living aspect of science has, however, been studied in the secret societies of the initiated, which have preserved the traditions of the kabala, the mysteries of hermetism and the practice of transmutation. The study of science is as much a religious question as an intellectual one, and worship at an altar should sustain and enlighten the worker in a laboratory. 'Chemistry, alchemy and hermetic philosophy form three steps of the ladder which leads the initiated from the laboratory, through artistic realization, to the oratory: 'Labora, Opera, Ora et Invenies.' "'

The modern alchemists also maintain that Darwin and his disciples appreciated but a small part of the great doctrine of evolution, which should be applied to the chemical elements as well as to living beings. The starting point in the evolution of elements is the ether (the universal astral fluid of the kabalists), the infinitely divisible particles of which form chemical atoms by agglomeration. This ether is condensed energy, and hence all matter is resolved into energy.

Energy, matter and motion form a trinity analogous to the Divine Trinity, one in substance, three in appearance. Matter is one in kind, and the diversity of chemical bodies results from differences in grouping and in motions of the constituent particles. Intelligence is allied in a mysterious way 
with matter and energy, forming another trinity. Every atom centralizes intelligence, is in itself a living entity and by a process of self-evolution yields the diverse natural bodies. " Ether is the father of hydrogen, from which are derived oxygen, nitrogen, carbon, etc., combinations due to etheric vortices." "Perhaps helium should precede hydrogen." This view of matter as a living entity is greatly insisted on, and the doctrine is called Hylozoism. An alchemist who expects to succeed must possess psychic power over the atoms, so that by the action of his will they shall group themselves to form the metal desired.

Such is the physical philosophy of modern alchemists; the kabalistic philosophy is by no means so clear, being closely linked to the Tarot, which signifies the 'hieroglyphs and algebraic calculations of the Primordial Genesis.'

Students of the mystical philosophy of the Hebrews discover profound occult significance in accidental similarities of widely differing objects and phenomena. The seven planets, seven days of the week, seven colors, seven orifices in the head, seven metals known to the ancients, seven archangels and seven infernal demons present to the truly kabalistic mind marvellous and precious analogies. In the 'Table of Concordance of Major Arcana' these correspondences are given: 'HethJustice-Elementary existence-Nizah-Cancer-June-Hydrogen-Fire.'

Jollivet-Castelot has written of Kabalistic Alchemy, and a perusal of his essays leaves in the mind of the uninitiated confused memories of colors, numbers, signs of the zodiac, alchemical operations as distillation, fixation and the like, the names of the sons of Jacob, certain precious stones, geometrical figures, Hebrew characters, Azoth, quintessence and the Devil, all discussed in a language as obscure as the symbolism portrayed. To conceal esoteric mysteries abbreviations are often used, but one does not have to be very deeply initiated to recognize in $\mathbf{P} . \cdot \mathrm{Ph} .{ }^{\circ}$ ' pierre philosophale,' and in $G . \cdot 0 . \cdot$. 'grand oeuvre.'

Astral light is an important factor in modern hermetism, and is related very closely to the 'radiant matter' of chemists and the 'ether' of physicists. "Astral light is the universal agent, the universal plastic mediator, the common receptacle of vibrations of motion and of the phantoms of form." It is also the Od of the Hebrews and of Baron von Reichenbach ; it is the great Thelesma of Hermes Trismegistus, and the control of this force constitutes the great arcana of practical magic. It heats, illuminates, magnetizes, attracts, repels, vivifies, destroys, coagulates, separates, crushes and gathers all things under the stimulus of powerful wills; it is a perpetual and transformable vibration. Its kabalistic figure, represented by the Serpent of Theogonies, is :

$$
\begin{array}{r}
\mathrm{Od}=+ \\
\mathrm{Ob}=- \\
\text { Aour }=\infty
\end{array}
$$

When the universal light magnetizes the universe it is called astral light; when it forms metals it is called Azoth, or the Mercury of the Sages; when it gives light to animals it is called animal magnetism. The astral undulations determine the position of the atoms or neutralize them. Herein lies the secret of transmutation, and it becomes the privilege of the hermetist to acquire the power of controlling this agent.

The adepts in this phase of hermetism still appeal to the Tabula Smaragdina of Hermes Trismegistus as the embodiment of alchemic lore. The ' Father of Alchemy,' who has been identified with Canaan, Noah's grandson, invented arithmetic, geometry, astronomy and music, taught writing to the Egyptians, and gave laws and religious rites to the people; he was 
perfectly acquainted with the ' philosophers' stone,' and, desirous that posterity should inherit the ${ }^{-}$wonderful secret, he had the whole art of creating gold engraved on an emerald tablet, which was placed in his sepulchre. Many years later this was removed by Sarah, Abraham's wife, and she concealed it in a cave near Hebron ; there it remained until again discovered by Alexander the Great. The inscription reads in part as follows :

"I speak not of fictitious things, but of that which is most true and certain. Whatsoever is below is like that which is above, and that which is above is like that which is below, to accomplish the miracles of one thing. Also since all things were made from one by the help of one, so all things are made from one thing by conjunction. The Father thereof is the Sun and the Mother thereof is the Moon ; the wind carries it in his belly, and the nurse thereof is the earth. * * * This thing has more fortitude than fortitude itself, because it will overcome every subtile thing and penetrate every solid thing. By it this world was formed. Hence proceed wonderful things which in this wise were established. For this reason I am called Hermes Trismegistus, because I possess three parts of the philosophy of the whole world. What I had to say about the work of the sun is completed."

Writers on modern alchemy discuss the marvels of palingenesis, of homunculi, and of gamahes; they write of the materialization of a metal through the medium (mediumnité) of a metal; they cite the 'Rules of Philalethes,' the works of George Ripley and of the Cosmopolite, and refer in the same essay to Berzelius, Berthelot and Moissan. We are told that "le diable est le singe de Dieu," and that the "Cherubim of the Ark of the Covenant symbolizes the male and the female of the Universe, the Alchemical Father and Mother," by the very authors who show acquaintance with the most recent advances in pure chemistry. In liquid fluorin they perceive a realization of the Alkahest, or universal solvent long sought by mediæval alchemists.

Accustomed to juggle with numbers, the kabalist finds abundant opportunity in the atomic weights of the elements, and he 'makes the most of his opportunity. When the arithmetical sum of the atomic weights of elements entering into a given compound chances to equal the atomic weight of gold, this accidental correspondence is seized upon as a pretext for claiming hermetic relationship between the two substances.

August Strindberg has devoted much study to such correspondence and points out the following:

$$
\begin{aligned}
\mathrm{K}_{2} \mathrm{MnO}_{4} & =197=\mathrm{Au} \\
\mathrm{Cu}_{2} \mathrm{Cl}_{3} & =196=\mathrm{Au} \\
\mathrm{Fe}_{3} \mathrm{~S} & =197=\mathrm{Au} \\
\mathrm{C}_{2} \mathrm{H}_{5} \mathrm{I}+\frac{1}{2} \mathrm{Br} & =197=\mathrm{Au}
\end{aligned}
$$

He uses both 196 and 197 as the atomic weight of gold to suit his purposes, and seems to be very weak in arithmetic, for the hypothetical body $\mathrm{Fe}_{3} \mathrm{~S}$ has a molecular weight of 200 .

The ammonium-ferrous-sulfate crystallized with six molecules of water, which chances to have a molecular weight equal to that of gold, is used by Strindberg as basis of the following experiment, which serves to show his method of reasoning and of operating.

Ammoniacal sulfate of iron $=392=\mathrm{Au}$ is perhaps the solution of the enigma ; sulfate of iron (green copperas), precipitates solutions of gold; to precipitate according to monist-chemistry is to enter as a factor into the reconstitution of the body of $a$ compound. Soak a strip of paper in a solution of sulfate of iron, and expose to the fumes of ammonia; the paper will assume a bluish-green color like that of the protoxid of gold. Dry the strip of paper over 
a lighted cigar and the paper will acquireia chestnut-brown color like that of the deutoxid of gold. Little by little metallic flakes of a golden yellow color appear, forming a non-solid (non-fixé) gold, when the sulfate of iron produces an auto-fecondation by self-precipitation. However, the golden flakes amalgamate with mercury, which property is not shared by iron. After showing by appropriate tests that iron is. still present the hermetic chemist proceeds to explain the reaction by assuming the formation of the hypothetical $\mathrm{Fe}_{3} \mathrm{~S}=196=\mathrm{Au}$, or of the imaginary compound

$$
\mathrm{Fe}_{2} \mathrm{O}_{3}+2 \mathrm{H}_{2} \mathrm{O}=196=\mathrm{Au},
$$

or of the

ferrous-ammonium-sulfate $=392=\mathrm{A} \dot{\mathrm{u}}_{2} ;$ and he adds, 'The chlorid of gold is reduced by the nicotine of the cigar.' Since, however, no reagent containing chlorin in any form was used in the experiment, this element must have been created at the same time with the gold, which, however, is ' in. complete' gold soluble in unmixed acids.

A preacher should never be judged by a single sermon, and to do justice to these nineteenth century alchemists, one more 'recipe for gold' may be transcribed. "Put into a crucible layers of sheet iron and of powdered vitriol; place over it another crucible pierced with a hole for respiration. Heat in an intense fire. But a flux must be added to the crucible to prevent melting, viz: One kilo litharge, one kilo clean white sand, mix and add to the crucible at a red heat. Remove with an iron spoon the yellow oil and put it aside. The two compounds have not lost weight. This oil is dry water, a fire, a salamander. *** You obtain a metal of a golden yellow, having a density of 24, not capable of being minted. This is changed into ordinary gold." With the exception of a few unimportant sentences, this is the entire recipe, but how the final transformation is to be effected is not given.

To acquire knowledge and power for successful hermetic labors, to become eligible for initiation in the occult societies, is no easy task. The aspirant must strive valiantly against the passions that assail him, casting out of his soul pride, anger, jealousy, hatred, avarice, hypocrisy, idleness. If the candidate for honors desires to become worthy of the name hermetic philosopher he must prove himself a Magian; he must learn to exercise his will on matter in all its forms, and to acquire this power he should practice crystal-gazing and reading in magic mirrors; to learn to perceive the invisible he must withdraw from the visible, imposing on himself psychic sleep, called by some hypnosis. As adjuncts to the attainment of the ideal mental state he should use perfumes, music and light; and eventually the astral body, separated from the physical body, will supply the intellectual, moral and material illumination indispensable to the Great Work.

It is rather discouraging to learn that, even after fulfilling all these hard conditions, no one can realize the perfection desired until he has passed through several of our planetary existences. The would-be alchemist must also follow the percepts of Albertus Magnus; he should be discreet, silent, and must not reveal the result of his labors; he must reside in an isolated place and choose the time and the hours for his tasks; he must be patient, assiduous and persevering, and he must be rich enough to bear the expenses of his pursuit. Besides ordinary chemical apparatus he should provide several objects indispensable to his work, a magic wand, a sword to dissolve the astral coagulations, a magic mirror, a brazier for perfumes, a wooden altar covered with a white cloth, and an alchemist's robe of white linen to be worn with a girdle 
embroidered in gold and silver. In all his chemical operations he must project psychic force into the reagents.

Bright prospects for the future of chemical science are claimed by this school of philosophers. Inorganic chemistry is destined to follow the lines in which inorganic chemistry has prospered; the formation, derivation, or rather the evolution of metalloids (so-called) and of metals will be realized through etheric cyclones, different degrees of condensation of hydrogen. Chemical bodies are of one kind only and they are all organic and living.

There is a growing belief among advanced chemists in the theory that the elementary bodies as known to us are compounds of a unique primary matter (protyle), and that transformation of one kind into a similar one is not beyond the bounds of possibility, but we do not think that the modern hermetists are pursuing the right path to accomplish this end; nor do we believe that the world of science is any nearer the coveted goal of alchemical avarice.

The revival of alchemical pursuits in France finds concurrent sympathy in other parts of the world. Especially does this pseudo-art flourish in India, where the Sannyassis, a caste initiated in occultism, practice the transmutation of tin, zinc, copper and mercury into silver, or at least into a metal resembling silver superficially. In the published recipes for effecting this change arsenic plays a prominent part, a substance used for the same deception by the alchemists of the Middle Ages. In China a belief in alchemy has existed from very early times ; reprints of ancient treatises are still for sale, and the experimental phase is quietly studied by semi-educated persons.

In the United States two notable events have occurred within twelve months, one of which seems to threaten financial revolution. A bold claim to manufacture gold of pure antimony has been made by Ed. ward C. Brice, of Chicago; having been refused a patent on his process by the United States Patent Office, he demanded a test to be made, and three assayers of the United States Mint conducted the trial under Brice's instructions. Needless to say, the experiment did not verify the claim; the assayers found that all commercial antimony contains a trace of gold, and that Brice did not even recover the whole of this by his process. Brice's previous record does not bear the full light of investigation, so that this attempt to revive alchemical practice is on a par with many that have preceded it.

Quite different seems to be the equally bold claim of Dr. Stephen H. Emmens, that he has discovered a body intermediate between silver and gold and capable of being changed into gold; this substance he has named argentaurum. Dr. Emmens, who is an Englishman by birth, is the author of many books on a great variety of topics; a treatise on logic, another on explosives, several novels and many papers on chemistry, electricity and metallurgy as well as some poems show his versatility. He is a member of several learned societies, and inventor of the high explosive 'emmensite.' Dr. Emmens has established a laboratory for the manufacture of gold from silver by a secret process in which mechanical treatment plays an important part. Since April 13,1897 , he has sold to the United States Assay Office six ingots of an alloy of silver and gold for the gross sum of $\$ 954$, as proofs of his success in transmutation. This matter having been exploited in the daily press, details need not here be reproduced.

In the United States, where education is so general and a shrewd, calculating, 'Yankee' spirit looks askance at such enticements, alchemy is not likely to flourish ; on the other hand, hermetism, the meta- 
physical phase of the philosophy seems far more likely to be cultivated by the devotees of theosophy and esoteric studies.

In conclusion, a passage from Lord Bacon: "I was ever of opinion that the philosopher's stone and an holy war were but the rendezvous of cracked brains that wore their feather in their heads."

H. Carrington Bolton.

WASHINGTON; D. C.

\section{SCIENCE IN EDUCATION.*}

DURING the year $1895-96$ there were in attendance at the colleges and universities of the United States nearly fifty thousand students who were pursuing courses leading to the degree of Bachelor of Arts, and of whom nearly ten thousand received that degree. In the various technological and professional schools there were sixty-six thousand students and nearly or quite fifteen thousand graduates. That is, those students seeking the so-called liberal education were less than forty per cent. of all the candidates for college degrees.

In none of the professional schools, with but few exceptions, is the possession of a college or university degree necessary for admission. A single medical school at the present time requires its matriculates to possess the bachelor degree, and some others will in the near future. In the theological schools a preparatory college education is more usual, but the whole number of theological students in the United States is relatively small, and does not seem to be rapidly increasing.

Nearly one-half of the professional students are those studying medicine, and of these I do not think more than five per cent. are graduates of other courses. Less than that percentage will be found among the engineering students, for reasons that will appear later. The profession of law,

* A presidential address before the thirtieth annual meeting of the Kansas Academy of Science. which is yet far behind the other professions in its educational requirements, has less than ten thousand students in attendance upon college instruction in our country, not one-third of the number of the medical students, though the members of the two professions in practice are much more nearly equal in numbers. A much larger proportion of arts graduates turn to the legal profession than to any other, in part due to the fact that the educational requirements of the legal profession are, in general, on so low a plane that the earnest young man is not content to enter upon his life's work with so slight a college preparation as it demands; in part because the ordinary college course offers better preparatory training for the legal profession than it does for any other, save the theological or pedagogic.

I am not aware of any statistics of the number of arts graduates among the active members of the professions in America, as a whole, but the number is clearly very small, certainly not one in ten, and I believe that there can be no question but that the percentage is steadily becoming less from year to year.

Our first impressions are that this fact is to be deplored. I believe, however, that it is rather matter of congratulation, inasmuch as it certainly means in the end better preparation for the active duties of life by the great body of professional men.

In no branch of education has there been more active progress than in that of medical education in the United States during the past fifteen years, and in none has there been a larger proportional increase of students. Twenty years ago, with almost no educational requirements for matriculation, nearly every medical institution in this country would graduate the average student after two courses of lectures, the second a repetition of the first, and each of but four or five months' duration. I have known students of average ability to re- 